\title{
Gemcitabine in Recurrent Meningioma
}

\author{
Satvik Khaddar ${ }^{1}$ Arti Bhelekar ${ }^{1} \quad$ Ochin Dale ${ }^{1}$ \\ ${ }^{1}$ Department of Medical Oncology, Tata Memorial Hospital, \\ Mumbai, Maharashtra, India
}

\section{Litty Varghese ${ }^{1}$ Vijay Maruti Patil ${ }^{1}$}

Address for correspondence Vijay Maruti Patil, MBBS, MD, DM Department of Medical Oncology, Tata Memorial Hospital, Mumbai, Maharashtra, India

(e-mail: vijaypgi@gmail.com).

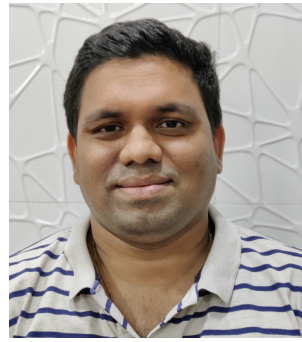

Dr Vijay M. Patil

\section{South Asian J Cancer:2021;9:261}

Meningiomas are the most common primary intracranial neoplasms. ${ }^{1}$ Grade I meningiomas are benign and managed by surgical resection alone. ${ }^{1}$ However, Grade II and III require adjuvant radiation and are characterized by their aggressive nature and high rates of recurrence. ${ }^{1}$ Unresectable recurrent high-grade meningiomas, refractory to radiotherapy, have a dismal prognosis with $26 \%$ progression-free survival of 6 months. $^{2}$ Systemic chemotherapy with interferon- $\alpha$ and somatostatin analogs, sunitinib, and bevacizumab has been tried with limited efficacy. ${ }^{3}$ Recently, Takeda et al demonstrated in vitro and in vivo activity of gemcitabine in high-grade meningiomas. ${ }^{4}$

Inspired by these results, at our institute, we have given gemcitabine to three patients of recurrent meningioma on compassionate grounds. All these three patients had earlier underwent surgery, radiation, followed by reradiation at first progression and were not a candidate for local therapy anymore. The time to progression over immediate previous treatment was 1 month in the first patient and 5 months in the second and third patients. The schedule of gemcitabine used was weekly $1,000 \mathrm{mg} / \mathrm{m}^{2}$ on day 1 , day 8 , and day 15 for a 28-day cycle. The best response was stable disease in all three patients. The number of cycles of gemcitabine received was 12,5 , and 10 in the first, second, and third patient, respectively. No major adverse events were observed except Grade

DOI https://doi.org/10.1055/s-0040-1721178 ISSN 2278-330X.

How to cite this article: Khaddar S, Bhelekar A, Dale O, Varghese L, Patil V. M . Gemcitabine in Recurrent Meningioma . South Asian J Cancer 2021;9(4):261.
II thrombocytopenia in one patient. Time to progression was 12 months in the first patient, 6 months in second patient, and 11 months in the third patient. The results are exciting and warrant further evaluation of this drug in this setting. Currently, a single-arm phase 2 trial is undergoing at our institute (CTRI/2019/02/017499) evaluating the efficacy of gemcitabine in recurrent Grade II/III meningiomas.

\section{Funding}

None.

\section{Conflicts of Interest}

There are no conflicts of interest.

\section{References}

1 Euskirchen P, Peyre M. Management of meningioma. Presse Med 2018;47(11-12 Pt 2):e245-e252

2 Kaley T, Barani I, Chamberlain M, et al. Historical benchmarks for medical therapy trials in surgery- and radiation-refractory meningioma: a RANO review. Neuro-oncol 2014;16(6): 829-840

3 Sioka C, Kyritsis AP. Chemotherapy, hormonal therapy, and immunotherapy for recurrent meningiomas. J Neurooncol 2009;92(1):1-6

4 Takeda H, Okada M, Kuramoto K, et al. Antitumor activity of gemcitabine against high-grade meningioma in vitro and in vivo. Oncotarget 2017;8(53):90996-91008

\section{2021. MedIntel Services Pvt Ltd.}

This is an open access article published by Thieme under the terms of the Creative Commons Attribution-NonDerivative-NonCommercial-License, permitting copying and reproduction so long as the original work is given appropriate credit. Contents may not be used for commercial purposes, or adapted, remixed, transformed or built upon. (https://creativecommons.org/licenses/by-nc-nd/4.0/)

Thieme Medical and Scientific Publishers Pvt. Ltd., A-12, 2nd Floor, Sector 2, Noida-201301 UP, India 